\title{
PENGARUH KOHESIFITAS KELOMPOK DAN KEPUASAN KERJA TERHADAP PRODUKTIVITAS GURU RAUDHATUL ATHFAL (RA) DI KABUPATEN BEKASI
}

\author{
Hanna Fauziyah*
}

\begin{abstract}
This research is aimed to investigate the influence of (1) group cohesiveness, (2) job satisfaction, (3) productivity of teachers the raudhatul athfal (kindergarten) school in the district of Bekasi. This research uses causal survey method by using Path Analysis Technicque. This study uses sample from 133 teachers in 20 raudhatul athfal (kindergarten) schools in the district of Bekasi region who are selected by using Slovin formula. The result of the study reveals that: first, there is a positive effect between group cohesiveness and productivity teachers in school. Second, there is a positive effect between job satisfaction and productivity teachers in school. Third, there is a positive effect between group cohesiveness and job satisfaction teachers in school.
\end{abstract}

Keywords : group cohesiveness, job satisfaction, and productivity

\section{PENDAHULUAN}

Pendidikan merupakan salah satu pilar penting dalam kehidupan masyarakat. Pendidikan yang bermutu dapat meningkatkan kualitas individu maupun masyarakat dalam usaha mengoptimalkan seluruh potensi manusia yang dilaksanakan secara terencana. Terkait dengan disahkannya Undang-Undang nomor 20 Tahun 2003 tentang Sistem Pendidikan Nasional dan Peraturan Pemerintah Republik Indonesia nomor 19 Tahun 2005 tentang Standar Nasional Pendidikan yang memberikan ruang kesetaraan antara posisi Madrasah/Sekolah islam dan Sekolah umum, upaya peningkatan kualitas pendidikan islam menjadi tantangan besar bagi Kementerian Agama. Salah satu peraturan tersebut menyebutkan adanya pendidikan anak usia dini merupakan pendidikan yang sangat fundamental untuk seorang anak, dikarenakan pendidikan anak usia dini ini merupakan suatu upaya pembinaan yang ditujukan kepada anak sejak lahir sampai usia enam tahun yang dilakukan melalui pemberian rangsangan pendidikan untuk membantu pertumbuhan dan perkembangan jasmani dan rohani agar anak memiliki kesiapan dalam memasuki sekolah dasar dan kehidupan tahap berikutnya. Selain itu sebagai wahana pendidikan dalam memberikan kerangka dasar terbentuk dan berkembangnya dasar-dasar pengetahuan, sikap dan keterampilan anak. Keberhasilan proses pendidikan pada masa dini merupakan dasar untuk proses pendidikan selanjutnya.

Saat ini pemerintah menjadikan guru sebagai salah satu pekerjaan profesional yang menuntut untuk menguasai dan memenuhi beberapa persyaratan yang tidak mudah berupa standar kualifikasi akademik dan kompetensi guru. Guru tidak hanya sebatas melaksanakan tugas di depan kelas, tetapi harus menunjukkan dedikasi tinggi untuk mengabdikan diri sebagai pendidik. Guru tidak sekedar menyampaikan ilmu tetapi mampu menjadi teladan yang digambarkan dengan perilakunya sehari-hari dan guru Pengurus Yayasan Pendidikan Islam Ar-Raudhah, Tambun, Bekasi 
harus mampu menguasai perangkat kompetensi tertentu untuk mampu mengajar dengan baik. Berdasarkan Peraturan Menteri Pendidikan Nasional Republik Indonesia Nomor 16 Tahun 2007 tentang Standar Kualifikasi Akademik dan Kompetensi Guru, dijelaskan bahwa standar kompetensi guru dikembangkan secara utuh dari 4 (empat) kompetensi utama, yaitu : (1) kompetensi pedagogik, (2) kepribadian, (3) sosial, dan (4) profesional. Keempat kompetensi tersebut terintegrasi dalam kinerja guru. Melalui guru, peserta didik dapat memperoleh transfer pengetahuan dan pemahaman yang dibutuhkan untuk pengembangan dirinya. Guru merupakan fasilitator utama di sekolah yang berfungsi untuk menggali, mengembangkan, dan mengoptimalkan potensi yang dimiliki oleh peserta didik sehingga ia bisa menjadi bagian dari masyarakat yang beradab. Berbagai peran ganda yang diemban guru bagi pengembangan peserta didik merupakan tugas mulia keprofesiannya, sekaligus sebagai komitmennya untuk mengembangkan pendidikan menjadi lebih baik dan berkualitas lagi, dalam rangka membangun masyarakat serta bangsa dan negara yang lebih beradab dan maju.

Permasalahan pendidikan yang dihadapi di Indonesia saat ini adalah rendahnya mutu pendidikan pada jenjang dan satuan pendidikan, khususnya pendidikan anak usia dini, pendidikan dasar, dan menengah. Salah satu faktor yang menyebabkan mutu pendidikan tidak mengalami peningkatan yaitu kebijakan dan penyelenggaraan pendidikan nasional yang menggunakan pendekatan educational production function atau input-output analisys tidak dilakukan secara konsisten. Pendidikan ini melihat bahwa lembaga pendidikan berfungsi sebagaii pusat produksi yang apabila dipenuhi semua input (masukan) yang diperlukan dalam kegiatan produksi tersebut, lembaga ini akan menghasilkan output yang dikehendaki. Pendekatan ini juga menganggap bahwa apabila input pendidikan seperti guru, buku, media pembelajaran, dan sarana serta prasarana lainnya dapat dipenuhi, mutu pendidikan (output) secara otomatis akan meningkat.

Produktivitas guru tercermin dalam perilakunya pada pelaksanaan tugas pokoknya sebagai guru dan keterlibatan pada kegiatan sekolah. Apakah dengan bangga, terpaksa atau hanya pemenuhan tanggungjawab secara moral saja. Produktivitas mengajar guru yang tinggi perlu ditunjang oleh kualifikasi akademik dan kompetensi yang memadai. Di samping itu, produktivitas mengajar guru dalam melaksanakan tugas perlu ditunjang oleh faktor yaitu faktor internal atau individu antara lain meliputi intelektualitas, keterampilan, kepribadian atau psikologis, fisik, motivasi, dan orientasi nilai; faktor organisasi meliputi sistem, peranan kelompok, supervisi, dan iklim organisasi; dan faktor lingkungan eksternal seperti keluarga, kondisi politik, kondisi ekonomi, kondisi sosial budaya, dan perubahan teknologi.

Perilaku yang sering ditunjukkan oleh guru dengan menampilkan pembelajaran hanya sebagai rutinitas saja untuk memenuhi syarat mengajar. Kendala yang sering terjadi adalah pembelajaran tanpa ada kreatifitas dan inovasi, kurangnya fasilitas dijadikan alasan utama. Ini berarti tingkat kohesifitas kelompok pada rekan guru maupun sekolah rendah, keinginan untuk mempersembahkan pembelajaran berkualitas kepada siswa tidak kuat. Setiap pekerjaan yang dikerjakan sebagai sumber pemasukan tambahan atau adanya tambahan honor yang diperoleh. Guru hanya mengajar untuk memenuhi tanggung jawabnya saja tanpa adanya kreatifitas dan inovasi baru dalam setiap proses mengajarnya. Hal tersebut menunjukkan bahwa sekolah memiliki permasalahan yang menunjukkan guru-guru memiliki kendala produktivitas dalam bekerja salah satunya adanya kendala kurangnya kekohesifan antar kelompok dan kepuasan kerja sehingga produktivitas guru rendah atau menurun. 
Kendala-kendala ini juga diungkapkan oleh Ketua IGRA Tahun 2014 di dalam laporan hasil tahunan Musyawarah Daerah (MUSDA) 2012-2015, yang mengatakan bahwa banyak guru RA yang memiliki masalah dan hambatan salah satunya rendahnya produktivitas karena kurangnya kohesifitas kelompok, kurangnya kekompakan dan interaksi antar guru maupun dengan kepala sekolah yang seharusnya dengan adanya kohesifitas memberikan dampak yang positif bagi guru untuk sharing dan mendapatkan ide melakukan kreatifitas dan inovasi di dalam dunia mengajar. Salah satu faktor positif untuk meningkatkan produktivitas guru adalah interaksi antar anggota kelompok, terjadi cukup sering sehingga hal tersebut membuat mereka mengenal satu sama lain dan merasa cocok karena adanya kesamaan tertentu dan bila ada suatu hal yang terjadi menjadi tujuan bersama dan menghendaki persaingan dari pihak eksternal, rasa kohesifitas akan cenderung meningkat demi mencapai kesuksesan bersama. Selain itu masalah lain yang muncul adalah kepuasan kerja yang tidak sesuai diterima guru pun menjadi salah satu faktor rendahnya produktivitas guru. Fasilitas yang belum sepenuhnya terfasilitasi dengan baik dan tunjangan gaji guru yang masih banyak dibawah rata-rata dalam penerimaan tunjangan tersebut yang diberikan Kementerian Pendidikan khususnya lebih kepada Kementerian Agama yang membuat penurunan kepuasan kerja guru menjatuhkan produktivitas guru-guru tersebut. Selain itu masalah yang sering terjadi adalah kreatifitas dan inovasi diri dalam mengembangkan kompetensi mengajar, kurangnya kualifikasi akademik yang dimiliki guru serta kurangnya komunikasi dan kekompakan antar guru maupun dengan kepala sekolah.

Produktivitas perlu ditunjang dengan adanya faktor internal yang muncul dari dalam diri atau faktor eksternal berasal dari luar individu guru. Motivasi kerja, sikap profesional, adanya kekohesifan kelompok serta disiplin kerja sangat diperlukan untuk dapat mencapai kinerja yang tinggi. Kesungguhan melaksanakan tugas timbul berkat kesadaran atas tugas yang menjadi tanggung jawab, motivasi untuk bekerja, serta sikapnya terhadap profesi. Faktor lain yang berasal dari luar individu yang diduga dapat menjadi faktor penentu prestasi kerja guru antara lain seperti adanya pembinaan, lomba guru sebagai wabah untuk meningkatkan kreatifitas dan pengakuan status yang dihargai. Disamping itu, lingkungan kerja dan iklim organisasi sangat diperlukan untuk mendorong pencapaian produktivitas guru. Produktivitas yang dicapai seseorang juga memiliki keterkaitan pada kepribadian, keterlibatan dan kekompakan kelompok guru terhadap sekolah atau organisasi, dan kepuasan kerja. Guru dengan produktivitas yang kuat, akan tetap berada dan melanjutkan dan bertahan dalam kenggotaannya pada suatu organisasi karena mereka ingin melakukannya atau dengan kata lain anggota menyukai organisasinya dan berkeinginan untuk ikut serta melakukan perubahan yang lebih baik di dalam sekolah atau organisasinya serta guru merasa termotivasi ketika bekerja dengan rekan guru lainnya. Guru dengan produktivitas yang tinggi dapat pengalaman, pengetahuan dan kreatifitas maupun untuk mencukupi kebutuhan seharihari. Jika guru menikmati pekerjaannya, merasa nyaman untuk tetap berada di organisasi untuk berbagi dan saling memotivasi sesama di dalam kelompoknya untuk melakukan kreatifitas dan inovasi dalam dunia mengajar, serta guru akan menjadi lebih kuat baik pengalamannya dalam suatu organisasi yang konsisten dengan harapanharapan dan memuaskan kebutuhan dasarnya, dan membantu melihat sejauh mana dirinya mampu memiliki tujuan yang sama dan sejalan dengan organisasi.

Pendekatan ini mencerminkan keinginan guru untuk menerima dan berusaha mewujudkan tujuan-tujuan organisasi dan menunjukkan keinginan para guru untuk terus bekerja bagi suatu organisasi bersama dengan rekan kerja guru lainnya untuk membuat perubahan dan inovasi-inovasi baru dalam proses mengajar. Selain itu adanya 
rasa puas karena memiliki pengalaman dan pengetahuan baru khususnya pendidikan, serta guru mampu mencukupi kebutuhan ilmu maupun materil untuk sehari-hari sehingga guru mempunyai produktivitas kerja yang kuat untuk tetap bekerja dan berada di sekolah karena mereka menginginkan untuk bekerja dan berada di sekolah itu. Dalam usaha untuk mengembangkan produktivitas ini banyak terkait dengan berbagai hal, salah satunya adalah yang menjadi ketertarikan peneliti adalah mengenai kohesifitas kelompok (group cohesiveness). Pendekatan kohesifitas kelompok guru berupaya untuk sejauh mana anggota kelompok tertarik satu sama lain dengan adanya kekompakan dalam mencapai satu tujuan kelompok yang diinginkan, sehingga Jika adanya kekompakan dalam suatu kelompok maka akan meningkatkan produktivitas individu dalam kelompok tersebut untuk saling memotivasi dan membantu dalam pencapaian tujuannya. Saling memberikan perlakuan yang fair, adil, dan suportif, memberikan kesempatan bagi tiap guru untuk menggunakan kemampuan secara penuh, memberikan kesempatan untuk mewujudkan diri dan memberikan kesempatan untuk berperan aktif dalam pengambilan keputusan-keputusan penting yang melibatkan pekerjaan mereka.

Dengan demikian pendekatan ini berusaha untuk lebih mendayagunakan keterampilan dan kemampuan guru untuk bekerja sama dengan rekan kerja guru lainnya untuk menyediakan lingkungan yang mendorong mereka meningkatkan keterampilan dan kompetensi mengajar yang lebih baik sehingga produktivitas guru pun akan meningkat karena saling adanya keterlibatan dan kekohesifan kelompok guru dalam suatu sekolah atau organisasi.

Selain kohesifitas kelompok, terdapat ada pula pengaruh kepuasan kerja (job satisfaction). Dimana kepuasan kerja juga memiliki efek positif pada produktivitas anggota kelompok yang terlibat di dalamnya. Guru yang puas dengan pekerjaannya cenderung untuk melakukannya lebih baik lagi, tidak menarik diri dan menjalani kehidupannya dengan lebih bahagia dan sehat. Dalam sekolah atau organisasi, guru yang puas dengan pekerjaannya cenderung akan menjadi produktif dan menguntungkan bagi rekan guru lainnya maupun kelompok organisasi. Adanya pengaruh psikologi individu yang sehat dan motivasi antar rekan guru akan meningkatkan kepuasan kerja yang berdampak pada produktivitas guru. Ketika mereka puas dengan pekerjaannya, maka akan berdampak pada perilaku positif sehingga berpengaruh pada kinerja dan produktivitas anggota kelompok guru. Akan tetapi, jika mereka merasa tidak puas, maka yang muncul adalah perilaku negatif yang mengakibatkan menurunnya produktivitas kerja guru. Berdasarkan uraian di atas, maka penelitian ini mengambil judul pengaruh kohesifitas kelompok dan kepuasan kerja terhadap produktivitas guru raudhatul athfal (RA) di Kabupaten Bekasi.

\section{Produktivitas}

Konsep produktivitas Produktivitas merupakan ukuran kuantitas dan kualitas kerja dengan pemanfaatan sumber kerja yang digunakan, produktivitas juga dapat diukur pada tingkat individu dalam kelompok. Seperti pernyataan Schermerhorn (2010;12) bahwa: "productivity is the quantity and quality of outputs relative the cost inputs of work performance with utilization considered. Productivity can be measured at the individual and group as well as organization." Sedangkan menurut John W. Newstroom (2011;13) berpendapat bahwa, "productivity is a ratio that the compares units of output with units of input, often against a predetermined standard. If more outputs can be produced from the same amount of inputs, productivity is improved." Bahwa produktivitas pada dasarnya merupakan rasio antara masukan (input) dan keluaran (output). Hal ini menegaskan 
bahwa produktivitas selalu bertumpu pada dua komponen utama yaitu input dan output. Jika kedua komponen tersebut memiliki besaran yang proporsional, maka hal itu akan dapat dikatakan produktif. Hal tersebut sesuai dengan pendapat Robbins dan Judge $(2009 ; 45)$ menjelaskan bahwa, "an organization is productive if it achieves its goals productivity is a performance measure including effectiveness and efficiency." Sebuah organisasi dapat dikatakan produktif jika ingin mencapai tujuannya, mengubah input menjadi output dengan biaya paling rendah, dan merupakan ukuran kinerja dengan efektif dan efisien. Sama seperti yang diungkapkan oleh Griffin (2013;307), yaitu "productivity is an economic measure of efficiency that summarizes the value of outputs relative to the value of the inputs used to create them." Dapat diartikan produktivitas juga merupakan nilai yang efisien mencakup nilai output yang relatif terhadap nilai input yang digunakan untuk menciptakan barang atau jasa. Jika dikaitkan produktivitas dalam pendidikan yaitu bagaimana menciptakan input dan menghasilkan output terbaik secara kuantitatif maupun kualitatif, sehingga pada akhirnya akan diperoleh output yang baik dan berkualitas (lulusan pendidikan terbaik), sesuai dengan kebutuhannya. Ivancevich et all (2008;2), mengungkapkan bahwa, "productivity is the relationship between inputs (e.g., hours of work, effort, use of equipment) and output (e.g., personal computer produced, customer complaints handled). The measures of productivity such as profit, sales, market share, student graduated, patient releases, documents processed, client services, and the like." Produktivitas adalah hubungan antara masukan (seperti, jumlah jam kerja, usaha, penggunaan peralatan) dan keluaran (seperti produksi, keluhan pelanggan yang ditangani). Langkah-langkah produktivitas mencakup profit, penjualan, lulusan siswa, proses dokumen, jasa, pelayanan dan sebagainya.

Berdasarkan konsep-konsep yang telah diuraikan di atas dapat disintesiskan produktivitas merupakan sebuah ukuran yang dijadikan pedoman untuk mengetahui sejauh mana sumber daya manusia, alam dan teknologi dapat dikelola dan dimanfaatkan untuk mewujudkan hal tertentu yang diinginkan. Dapat disintesiskan produktivitas adalah kualitas dan kuantitas kerja yang dihasilkan oleh seseorang dengan memanfaatkannya secara efektif dan efisien dalam penggunaan sumber daya dengan indikator (1) pemanfaatan sumber daya, (2) ketepatan penggunaan waktu, (3) kualitas pelayanan, (4) pencapaian tujuan.

\section{Kohesifitas Kelompok}

Kohesifitas merupakan kecenderungan suatu kelompok untuk setia menjadi bagian dalam sebuah kesatuan kelompok. Definisi ini diungkapkan oleh Mc Shane dan Von Glinow (2010;234) bahwa "group cohesiveness refers to the degree off attraction people feel toward the team and their motivation to remain members." Senada dengan definisi diatas, Daft $(2010 ; 580)$ mendefinisikan "team cohesiveness is defined as the extent to which members are attracted to the team and motivated to remain in it." Kedua definisi di atas menyatakan kohesifitas kelompok merupakan adanya daya tarik anggota dengan kelompoknya dan termotivasi untuk tetap ada di kelompok itu. Hal itu juga dinyatakan oleh Harris and Hartman (2002;106) juga mendefinisikan, "cohesiveness is the strength of the feeling of unity group members have for the group as a whole and for other people in group." Dimana kohesifitas kelompok dikatakan juga sebagai perasaan kuat untuk bersatu dengan anggota dan adanya komitmen dalam kelompok secara keseluruhan sama seperti yang disampaikan oleh Slocum dan Hellriegel $(2009 ; 346)$ bahwa, "cohesiveness is the strength of the member's desire to remain in a team and their commitment to it." Menurut Kreitner dan Kinicki (2010;319) mendefinisikan kohesifitas sebagai berikut: "a sense of we-ness emerges to transcend individual differences and motives. Cohesive group members stick together for one or 
both of the following reason: (1) because they enjoy each other's company or (2) because they need each other to accomplish a common goal." Pernyataan di atas dapat dijelaskan bahwa kohesifitas merupakan rasa ke-kita-an yang muncul untuk mengatasi kohesifitas individu dan tujuan. Kelompok yang kohesif yang bersatu disebabkan karena mereka menikmati kebersamaan.

Dari beberapa konsep di atas, maka dapat disintesiskan bahwa kohesifitas kelompok adalah kesetiaan dan kekompakan dalam sebuah kelompok karena adanya kesamaan tujuan yang ingin dicapai serta adanya komitmen setiap anggotanya untuk tetap berada di kelompok, dengan indikator seperti (1) interaksi antar anggota kelompok, (2) kebersamaan kelompok, (3) kesamaan tujuan kelompok dan (4) pencapaian kelompok.

\section{Kepuasan Kerja}

Dalam kehidupan berorganisasi, kepuasan kerja biasanya digunakan sebagai dasar ukuran tingkat kematangan organisasi. Salah satu gejala yang menyebabkan kurang baiknya kondisi kerja suatu organisasi adalah rendahnya kepuasan kerja Sebaliknya kepuasan kerja yang tinggi menunjukan bahwa organisasi telah dikelola dengan baik. Menurut Wagner dan Hollenbeck $(2010 ; 106)$ berpendapat bahwa, "job satisfaction is a pleasurable feeling that results from the perception that one's job fulfills or allows for the fulfillment of one's important job values." Menurut Colquitt (2013;96) mengungkapkan, "job satisfaction is defined as a pleasurable emotional state resulting from appraisal of one's job or job experiences." Dari kedua definisi di atas dijelaskan bahwa kepuasan kerja adalah suatu keadaan perasaan emosional dan keyakinan yang dihasilkan dari persepsi pengalaman dan pekerjaan seseorang telah terpenuhi dengan tugas yang telah dilaksanakannya.

Anggota yang puas adalah anggota yang produktif, dimana tidak adanya kesenjangan antara yang diinginkan dengan kenyataannya, karena setiap dari tugas pekerjaannya telah terpenuhi. Kepuasan kerja dapat diartikan sebagai sebuah prestasi, pengakuan, tanggung jawab, dan kemajuan. Hal ini diutarakan oleh Miner $(2005 ; 63)$ bahwa, "job satisfaction is viewed as an outgrowth of achievement, recognition (verbal), the work itself (challenging), responsibility, and advancement (promotion)." Lebih lanjut menurut Luthans $(2011 ; 141)$ mengatakan, "job satisfaction is a result of employee's perception of how well their job provides those thing that are viewed as important." Kepuasan kerja merupakan hasil dari persepsi pekerjaan tentang bagaimana pekerjaannya memberikan sesuatu yang dianggap penting. Kepuasan kerja seseorang dapat diartikan sebagai hasil evaluasi terhadap tanggung jawab pada pekerjaannya, seperti yang dikatakan oleh Mc Shane dan Vonn Glinow (2010;108), "a person's evaluation of his and her job and work context, is probably the most studied attitude in organizational behavior." Senada dengan pendapat yang ungkapkan oleh Robbins dan Judge $(2009 ; 114)$ bahwa, "a positive feeling about job resulting from a evaluation of its characteristics is clearly broad." Kedua pendapat ini menjelaskan bahwa kepuasan kerja merupakan evaluasi dari perasaan positif terhadap tanggung jawab pekerjaannya yang menjadikan karakteristik dari kepuasan kerja itu sendiri.

Dari pendapat di atas dapat disintesiskan bahwa kepuasan kerja adalah respon perasaan menyenangkan dan tidak menyenangkan yang dirasakan oleh individu sebagai akibat dari pengalaman, evaluasi, penilaian kerja yang meliputi indikator (1) perasaan terhadap pekerjaan dengan kepribadian, (2) perasaan terhadap rekan kerja, (3) perasaan terhadap imbalan pekerjaan, (4) perasaan terhadap kondisi pekerjaan. 


\section{METODE PENELITIAN}

Penelitian ini menggunakan metode survey dengan teknik analisis jalur (path analysis). Data penelitian ini dikumpulkan dengan cara memilih sampel dalam populasi. Populasi terjangkau dalam penelitian ini adalah seluruh guru RA di kabupaten Bekasi berjumlah 200 guru. Dan perhitungan dengan menggunakan slovin, maka diperoleh jumlah sampel sebanyak guru yang dijadikan sampel frame dalam penelitian ini. Teknik pengumpulan data yang digunakan untuk penelitian ini adalah kuesioner. Selanjutnya dilakukan uji coba instrumen kepada 25 guru untuk menentukan butir-butir instrumen yang valid dan reliabel. Teknik analisis data dilakukan dengan statistika deskriptif dan statistika inferensial dengan terlebih dahulu melakukan uji prasyarat analisis yaitu normalitas populasi dan analisis regresi.

\section{HASIL PENELITIAN DAN PEMBAHASAN \\ Pengaruh Kohesifitas Kelompok terhadap Produktivitas}

Dari hasil pengujian hipotesis pertama dapat disimpulkan bahwa terdapat pengaruh langsung positif kohesifitas kelompok terhadap produktivitas dengan nilai koefisien korelasi sebesar 0,444 dan nilai koefisien jalur sebesar 0,358. Ini memberikan makna kohesifitas kelompok berpengaruh langsung terhadap produktivitas.

Hasil penelitian ini senada dengan pendapat beberapa ahli di antaranya adalah Robbins menjelaskan bahwa kohesifitas merupakan salah satu faktor sejauh mana anggota kelompok tertarik satu sama lain dengan adanya kekompakan dalam mencapai satu tujuan kelompok yang diinginkan. Robbins (2011:47) juga menambahkan bahwa : "cohesiveness influences productivity. Research has generally shown highly cohesive groups are more effective than those with less cohesiveness, but the relationship is more complex than merely allowing us to say high cohesiveness is good. First, high cohesiveness is both a cause and outcome of high productivity. Second, the influences is moderated by the degree to which the group's attitude aligns with it formal goals or those of the larger organization of which it is part." Kohesifitas mempengaruhi produktivitas, bahwa adanya penelitian yang menunjukkan secara umum kelompok yang sangat kohesif akan lebih efektif daripada mereka yang kurang memiliki kohesifitas dalam kelompoknya. Adanya kohesifitas yang tinggi merupakan sebab dan akibat dari produktivitas yang tinggi. Kemudian sejauh mana sikap kelompok sejalan dan beriringan satu sama lainnya dalam mencapai tujuan dari kelompok tersebut. Jika adanya kekompakan dalam suatu kelompok maka akan meningkatkan produktivitas individu dalam kelompok tersebut untuk saling memotavasi dan membantu dalam pencapaian tujuannya.

Robbins dan Judge (2009:291) juga mengatakan dalam bukunya yang berbeda, yaitu "cohesiveness affects group productivity. Studies consistently show thaht the relationship between cohesivenss and productivity depents on the group's performance related norms." Bahwa kohesifitas mempengaruhi produktivitas kelompok, dimana produktivitas ini diarahkan pada individu atau anggota kelompok dalam menjalankan pekerjaannya. Penelitian mereka menunjukkan adanya konsistensi antara kohesifitas atau kekompakan dan produktivitas tergantung pada kinerja anggota kelompok. Sedangkan menurut Slocum dan Hellriegel (2009:346) menjelaskan bahwa, "the impact on effectiveness that is team performance and producitivity can be affected by cohesiveness." Dengan adanya dampak pada efektifitas kinerja dan produktivitas dapat dipengaruhi adanya kohesifitas dari kelompok.

Dari penelitian ini dapat disimpulkan bahwa, kohesifitas kelompok berpengaruh langsung positif terhadap produktivitas. Artinya, kekuatan kohesifitas kelompok 
mengakibatkan peningkatan produktivitas guru raudhatul athfal (RA) di Kabupaten Bekasi.

\section{Pengaruh Kepuasan Kerja Terhadap Produktivitas}

Dari hasil pengujian hipotesis kedua dapat disimpukan bahwa terdapat pengaruh langsung positif kepuasan kerja terhadap produktivitas dengan nilai koefisien korelasi sebesar 0,416 dan nilai koefisien jalur sebesar 0,320. Ini memberikan makna kepuasan kerja berpengaruh langsung terhadap produktivitas.

Hasil penelitian ini senada dengan pendapat beberapa ahli di antaranya adalah yang diungkapkan oleh Locke (2003;90), bahwa: “job satisfaction matters. Employees who are satisfied with their jobs tend to perform better, withdraw less, and lead happier and healthier lives. Organizations whose employees are satisfied with their jobs are more likely to be productive and profitable." Menjelaskan bahwa kepuasan kerja adalah penting, pegawai atau anggota yang puas dengan pekerjaannya cenderung untuk melakukannya lebih baik lagi, tidak menarik diri dan menjalani kehidupannya dengan lebih bahagia dan sehat. Dalam organisasi, anggota yang puas dengan pekerjaannya cenderung akan menjadi produktif dan menguntungkan bagi anggota maupun kelompok organisasinya. Adanya pengaruh psikologi individu yang sehat dan motivasi antar anggota kelompok akan meningkatkan kepuasan kerja yang berdampak pada produktivitas anggota kelompok. Dalam hal ini dijelaskan juga pengaruh kepuasan kerja terhadap produktivitas oleh Mullins (2005;772) yang mengatakan: "good people management practices, a positive psychological contract and a supportive organization culture lead to commitment, job satisfaction and a willing controbution from employees. These characteristics positively feed through to higher productivity and profitability." Bahwa adanya kontrak psikologis yang positif dan budaya organisasi yang mendukung komitmen, kepuasan kerja dan kontribusi dari pegawai atau anggota kelompok tersebut yang menjadi karakteristik positif untuk menduking produktivitas yang lebih tinggi. Selain itu Robbins dan Coulter $(2012 ; 396)$ menjelaskan bahwa, "job satisfaction positively influences productivity, lowers absenteeism levels, lowers turnover rates, promotes positive customer satisfaction, moderately promotes OCB, and helps minimize workplace misbehavior." Kepuasan kerja berpengaruh positif terhadap produktivitas, menurunkan tingkat absensi, menurunkan tingkat turn-over, mempromosikan kepuasan pelanggan yang positif, mempromosikan OCB, dan membantu meminimalkan perilaku kerja. Dengan penjelasan ini terlihat bahwa kepuasan kerja mempunyai pengaruh terhadap beberapa output organisasi salah satunya produktivitas. Output ini dapat diartikan sebagai hasil penilaian kerja yang positif adalah harapan setiap orang karena dapat memicu dan memotivasi seseorang untuk melaksanakan tugasnya dengan baik. Dampak dari sesuatu yang menyenangkan itu akan diterima oleh seseorang dan akan ditunjukkan dalam bentuk produktivitas. Produktivitas akan menurun apabila sesuatu yang diterima tidak sesuai harapan. Begitu pula sebaliknya produktivitas semakin tinggi apabila sesuatu yang diterimanya menyenangkan.

Dari penelitian ini dapat disimpulkan bahwa, kepuasan kerja memiliki pengaruh langsung positif terhadap produktivitas. Artinya, peningkatan kepuasan kerja mengakibatkan peningkatan produktivitas guru raudhatul athfal (RA) di Kabupaten Bekasi dalam menjalankan dan menghasilkan pekerjaannya yang maksimal.

\section{Pengaruh Kohesifitas Kelompok Terhadap Kepuasan Kerja}

Dari hasil pengujian hipotesis ketiga dapat disimpulkan bahwa terdapat pengaruh langsung positif kohesifitas kelompokterhadap kepuasan kerjadengan nilai 
koefisien korelasi sebesar 0,267 dan nilai koefisien jalur sebesar 0,267. Ini memberikan makna kohesifitas kelompok berpengaruh langsung terhadap kepuasan kerja.

Hasil penelitian ini senada dengan pendapat beberapa ahli di antaranya adalah yang dijelaskan oleh Quick dan Nelson $(2013 ; 280)$ bahwa, "the interpersonal glue that makes the members of a group stick together is group cohesion. Group cohesion can enhance job satisfaction for members." Menjelaskan adanya hubungan saling memotivasi antar individu akan membuat anggota kelompok bersatu yang menjadikan kohesifitas atau kekompakan kelompok berujung pada kepuasan kerja bagi anggota kelompok itu sendiri. Selain itu, kohesifitas kelompok tidak hanya meningkatkan kepuasan kerja pada anggota kelompoknya, melainkan juga komitmen kerja pada organisasinya. Hal tersebut dijelaskan oleh Slocum dan Hellriegel $(2009 ; 346)$ bahwa, "the impact of cohesiveness can be effective, if the team is successful in reaching those goals, the positive feedback of its successes may heighten member commitment and satisfaction." Dampak kohesifitas atau kekompakan yang efektif adalah jika kelompok berhasil dalam mencapai tujuan tersebut, dan mendapatkan umpan balik yang positif dari keberhasilan yang dapat meningkatkan komitmen dan kepuasan pada anggota kelompok tersebut. Menurut Schermerhorn et all (2012;179) menjelaskan kembali bahwa, "the cohesiveness of a group or team is the degree to which members are attracted to and motivated to remain part of it. We might think of it as the "feel good" factor that causes people to value their membership on a team, positively identify with it, amd strive to maintain positive relationships with other members. Feeling of cohesion can be of need satisfaction, often providing a source of loyalty, security, and esteem for team members." Kohesifitas atau kekompakan kelompok adalah sejauh mana anggota yang tertarik dan termotivasi untuk tetap menjadi bagian dari organisasi itu. Kita mungkin berpikir bahwa "merasa baik" karena adanya faktor yang menyebabkan orang untuk menghargai keanggotaan mereka dalam sebuah kelompok dan mengidentifikasi secara positif serta berusaha untuk mempertahankan hubungan positif dengan anggota lainnya. Perasaan kompak ini merupakan kebutuhan dari kepuasan yang sering dijadikan sumber loyalitas, keamanan, dan harga diri bagi anggota timnya. Dengan adanya kekompakan pada sebuah kelompok, maka akan menghasilkan banyak hal salah satunya adalah kepuasan kerja bagi anggota kelompoknya.

Dari penelitian ini dapat disimpulkan bahwa, kohesifitas kelompok berpengaruh langsung positif terhadap kepuasan kerja. Artinya, kekuatan kohesifitas kelompok mengakibatkan peningkatan kepuasan kerja guru raudhatul athfal (RA) di Kabupaten Bekasi.

\section{PENUTUP}

Kesimpulan: 1) Kohesifitas kelompok berpengaruh langsung positif terhadap produktivitas. Artinya adanya kohesifitas kelompok mengakibatkan peningkatan produktivitas guru Raudhatul Athfal (RA) di Kabupaten Bekasi. 2) Kepuasan kerja berpengaruh langsung positif terhadap produktivitas. Artinya adanya kepuasan kerja mengakibatkan peningkatan produktivitas guru Raudhatul Athfal (RA) di Kabupaten Bekasi. 3) Kohesifitas kelompok berpengaruh langsung positif terhadap kepuasan kerja. Artinya adanya kohesifitas kelompok mengakibatkan peningkatan kepuasan kerja guru Raudhatul Athfal (RA) di Kabupaten Bekasi.

Saran: 1) Bagi Kepala Sekolah sebagai pemimpin tertinggi sekaligus contoh bagi para guru agar mampu membimbing, mengarahkan serta meningkatkan tanggung jawab serta rasa kepemilikan yang tinggi terhadap sekolah dan sikap peduli terhadap profesi guru, menciptakan sistem penghargaan yang mampu menghasilkan kualitas guru 
dengan semangat kerja yang tinggi, memiliki target dalam bekerja, patuh terhadap peraturan yang berlaku, serta memperhatikan kesejahteraan para guru serta membuat suasana kerja yang nyaman, harmonis, serta kondusif sehingga mampu mendorong para guru untuk bersedia memberikan loyalitasnya dan melakukan tugas melebihi tugas formalnya sebagai guru. 2) Bagi para guru Raudhatul Athfal (RA) Kabupaten Bekasi agar memandang bahwa dalam melaksanakan tugasnya sebagai guru harus memiliki motivasi internal serta kecintaan terhadap pekerjaan yang dijalani, sehingga guru dapat merasakan adanya ketulusan dan keikhlasan terhadap profesi, tanggung jawab serta kepemilikan yang akan mendorong dirinya untuk melakukan pekerjaannya sebaik mungkin serta melebihi tugas formalnya. Guru yang memiliki kekompakan dan adanya hubungan komunikasi yang baik antar rekan guru, akan menimbulkan produktivitas guru yang tinggi. Selain itu, adanya kepuasan kerja seperti mendapatkan pengalaman dan ilmu-ilmu kreatif akan berdampak positif pada produktivitas guru. Sikap seperti inilah yang akan melahirkan guru yang memiliki perilaku produktivitas yang tinggi. 3) Bagi para peneliti lain agar penelitian ini dapat dijadikan rujukan dalam penelitian lanjutan terkait dengan produktivitas guru karena ruang lingkup penelitian ini terbatas pada kohesifitas kelompok dan kepuasan kerja. 


\section{DAFTAR RUJUKAN}

Adeleke O. Banwo, Jianguo Du dan Uchechi Onokala. (2015). The Impact of Group Cohesiveness on Organizational Performance: The Nigerian Case. International Journal of Business and Management. Canadian Center of Science and Education. China. Vol. 10, No. 6

Dennis J. Moberg dan David F. Caldwell. (2003). Interactive Case in Organizational Behavior. USA: Scott, Foresman and Company.

Departemen Pendidikan Nasional. (2003). Undang-Undang Republik Indonesia Nomor 20 Tahun 2003 tentang Sistem Pendidikan Nasional. (Jakarta: Pusat Data dan Informasi Pendidikan, Balitbang-Depdiknas.

Edwin A. Locke. (2003). Principle of Organizational Behavior. United Kingdom: Blackwell Publishers.

Fred Luthans. (2011). Organizational Behavior An Avidence-Based Approach. New York: McGraw-Hill.

Gareth R. Jones dan Jennifer M. George. (2006). Contemporary Management, $3^{\text {rd }}$ Edition. New York: McGraw Hill.

Ivancevich, Konopaske dan Matteson. (2008). Organizational Behavior of Management, Eighth Edition. USA: McGraw-Hill.

James C. Quick dan Debra L. Nelson. (2013). Principle of Organizational Behavior, Reality and Challenges. South-Western: Cengage Learning.

Jason A. Colquitt, Jeffrey A. Lepine dan Michael J. Wesson. (2013). Organizational Behavior Improving Performance and Commitment in Workplace Third Edition. New York: McGraw-Hill. Jennifer M. George dan Gareth R. Jones. (1999). Understanding and Managing Organizational Behavior. USA: Addison-Wesley Publishing Company, Inc.

John B. Miner. (2005). Organization Behavioral Essential Theories of Motivation and Leadership. USA: M. E. Sharpe, Inc.

John R. Schermerhorn. (2010). Introduction of Management, Tenth Edition. ASIA: John Wiley \& Sons, Inc.

John W. Newstroom. (2011). Organizational Human Behavior at Work, Twelfth Edition (New York: McGraw-Hill.

John R. Schermerhorn et all. (2012). Organizational Behavior, Twelfth Edition. Asia: John Wiley \& Sons, Inc.

Kocsis dan David William. (1997). Productivity in work team: The effects of the type of team and interpersonal group cohesiveness. Doctoral Dissertations. Paper AAI9737415, No. 
154, http://digitalcommons.uconn.edu//dissertations/AAI9737415 (Diakses pada tanggal 2 November, 2015, pukul 20.30 WIB)

Laurie J. Mullins. (2005). Management and Organizational Behavior, Seventh Edition. England: Pearson Education Limited.

Lavada Cleare. (2013). Personality as a Predictor of Job Satisfaction: Study ofthe Relationship between Personality and JobSatisfaction amongst Workers in the Bahamas. Journal of Management Research, Macrothink Institute. Bahamas. Vol. 5, No. 3.

Mohammed Jassim Uddin, Rumana Huq Luva dan Saad Maroof Hossian. (2013). Impact of Organizational Culture on Employee Performance and Productivity: A Case Study of Telecommunication Sector in Bangladesh. International Journal of Business and Management. Canadian Center of Science and Education. Bangladesh. Vol. 8, No. 2.

Laporan Musyawarah Daerah (MUSDA) III 2010 PD IGRA Kabupaten Bekasi 2010-2015.

O. Jeff Harris dan Sandra J. Hartman. (2002). Organizational Behavior. USA: The Haworth Press, Inc.

Petri, Bockerman dan Pekka, Ilmakunnas. (2010). The Job Satisfaction-Productivity Nexus: A Study Using Matched Survey and Register Data, HECER-Helsinki Center of Economic Research. The University of Helsinki. Finland, No. 297.

Peraturan Menteri Agama Republik Indonesia Nomor 90 Tahun 2013.

Richard L. Daft. (2010). New Era of Management Ninth Edition. Canada: Cengange Learning.

Ricky W. Griffin. (2013). Management Principles and Practices. South-Western: Cengage Learning.

Robert Kreitner dan Angelo Kinicki. (2010). Organizational Behavior, Ninth Edition. New York: Mc Graw-Hill.

Robert L. Mathis dan John H. Jackson. (2011). Human Resource Management. SouthWestern: Cengange Learning.

Rohiyat. (2010). Manajemen Sekolah. Bandung: PT Refika Aditama.

Sedarmayanti. (2009). Sumber Daya Manusia dan Produktivitas Kerja. Bandung: CV Mandar Maju.

Schermerhorn et all. (2012). Organizational Behavior, Twelfth Edition. Asia: John Wiley and Sons.

Stephen, Robbins. (1988). Essential of Organizational Behavior, Second Edition. New jersey: Prentice-Hall International. 
Stephen P. Robbins dan Timothy A Judge. (2009). Organizational Behavior, Fourteenth Edition. New Jersey: Pearson.

Stephen P. Robbins dan Mary Coulter. (2012). Management Eleventh Edition. New Jersey: Pearson Prentice Hall.

Stephen P. Robbins. (2011) Organizational Behavior Concepts, Controversies, and Applications. USA: Prentice Hall.

Slocum dan Hellriegel. (2009). Principle of Organization Behavior,Twelfth Edition. SouthWestern: Cengage Learning.

Steven L. Mc Shane dan Mary Ann Von Glinow. (2010). Organizational Behavior Emerging Knowledge and Practice for the Real Word, Fifth Edition. New York: McGraw-Hill.

Wagner dan Hollenbeck. (2010). Organizational Behavior Securing Competitive Advance. New York: Madison Ave.

http://arfaumg.blogspot.co.id/2012/05/masalah-kualitas-pendidikan-di.html Diakses pada tanggal 5 November 2015 